\title{
School Leaders' Resilience amidst Pandemic in the District of Victoria
}

\author{
Nilda V. San Miguel \\ nildssanmiguel@gmail.com \\ Department of Education, Lumban, Laguna, Philippines, 4014
}

\begin{abstract}
This study focused on resiliency of school leaders in Victoria District, Laguna, Philippines amidst pandemic. Seventeen elementary and secondary principals became part of the study by undergoing survey questions pertaining to the (1) promotion of community cohesiveness, (2) sustained communication, (3) attention to mental and psychosocial health and, (4) welcoming feedback. The author made use of qualitative and quantitative techniques in doing research as responses to survey questions were recorded, sorted, analyzed and, interpreted. It was found out that school heads of Victoria District have very high resiliency in terms of promotion of community cohesiveness, sustained communication, attention to mental and psychosocial health, and welcoming feedback. School heads promote community cohesion by engaging families and stakeholders in all the school programs and by using various formats during distance learning. Some schools provided unstructured opportunities for small-group connections. To sustain communication among the internal and external stakeholders of the school community, school head gave clear and direct communication using different platforms based on DepEd Orders and memorandums. To combat epidemic, school heads conducted orientations, meetings and webinars for the entire community through social media platforms about mental and psychosocial wellness because when schools clearly prioritized attention to mental health, it greatly enhanced feelings among students and adults that they were genuinely valued. Welcoming feedback was one of the top priorities of school heads to receive a clear response from the community, also both teachers and learners, as they share their feelings and receive specific feedback on what was going well at school and what might be improved. Recommendations to school heads were laid down to sustain their resiliency at all cost.
\end{abstract}

Keywords: resilient; community; mental; psychosocial; health; feedback

\section{Introduction}

The striking question being heard most of the time whenever a school head gets a chance to share own work and personal life stories. Knowing the great responsibilities being put into their shoulders, plus the hustle and bustle of the profession - it is no doubt that this kind of question is something that can be commonly asked to any of them.

In the context of having too much to do and much to prepare to, undeniably, school heads and administrators are the first ones to spring to mind. Having to go through a lot of physical and even mental work demands, exhaustion is already anticipated. Moreover, the pressure to strive for competence and aim for professional growth and development is something that is always expected from them.

The idea to juggle everything in between makes the leading and managing experience to be just way too burdensome. As if everything must be done accordingly, that one wrong move will mess up all the things they have worked for - losing the morale and the high spirit they have for the demanding profession.

As a further matter, this concern is not only popular to specific group of leaders alone. Other 
academic administrators including supervisors and subject specialists also walk their way through the same narrow and difficult part of performing their tasks along various factors which hinders effective management and efficient work assignment implementation.

Not to mention the impact of the global pandemic in the education sector and its implication to the mental well-being of school heads and teachers. Amid all the struggle, what keeps the flame burning, is the resiliency of all the school heads who willingly devotes their life into the profession - even if it is less good than what they had before.

But how do they really do it?

Looking back at the years of extreme hard work and sacrifice. One thing that helped them to keep going is their attitude. Perspective on various work-life conundrum and standing neutral on conflicts earned them a notable reputation. This badge of honor puts pride to their being not only as a school leader, but more so in their individual achievements.

But all these would not be possible without the help of one another, as for any leader, their strength comes from the people surrounding them - that includes teachers, stakeholders, learners, and their vision. For without all of these, none of their efforts would matter.

The primary requirement to handle everything that comes with leadership is resilience. Problems come and go - and these difficulties must be handled with optimism and hope. Through this study, an indepth presentation of school heads resiliency will be shown.

\subsection{Background of the Study}

Amidst the public health emergency brought about by the COVID-19 pandemic, the Department of Education (DepEd) is committed to ensure unhampered delivery of basic education services to its learners and the community, in line with the constitutional mandate of the State "to establish, maintain and support a complete, adequate, and integrated system of education relevant to the needs of the people, the country and society-at-large," pursuant to Section 2 (1), Article XIV of the 1987 Constitution, as reiterated in Republic Act (RA) No. 10533, or the Enhanced Basic Education Act of 2013.

COVID-19 is an unprecedented event that brings adverse effects to different countries, including the Philippines. This disease greatly affected education in the Philippines from March 2020 up to the present. Hundreds of school closures are implemented because of the danger that this disease could bring. Due to its massive impact on education, educational institutions in the country take educational countermeasures to continue educating the students despite the COVID-19 difficulties. They strengthen the educational planning and health measures in every school to provide students and teachers with an opportunity to continue learning while preventing the spread of the virus. The educational system in many schools was switched from face-toface to distance learning. Some teachers made modules for modular instructions while some recorded and uploaded their lessons for the students to access online. The truth is, private and public schools are not prepared to implement this kind of system, but because education is vital for the development of the children as well as the country, many schools opted for distance education.

This is the reason why the why the Department of Education issued DepEd Order (DO) No. 012, s. 2020, "Adoption of the Basic Education Learning Continuity Plan (BE-LCP) for School Year 2020-2021 in the light of the COVID-19 Public Health Emergency," DepEd shall employ multiple learning delivery modalities (LDMs) to ensure the continued provision of learning opportunities to its learners, while protecting the health and safety of both its personnel and learners. This can be done through blended learning, distance learning, and home-schooling. This is the possible solution so that learning would continue and to apply the school heads' resiliency.

The respondents of this study are the 17 public elementary school principals in the elementary and secondary in Victoria District, Division of Laguna. School Year 2020-2021. 


\subsection{Theoretical Framework}

As this study would like to explore aspects in which school leaders can thrive in a challenging time like COVID-19 pandemic, the principle discussed by Patterson and Keheller (2005) in their book entitled "Resilient School Leaders: Strategies for Turning Adversity into Achievement" provide six strengths that will enable resilient leaders to powerfully influence organization culture:

* Accurate assessment of the past and current reality

* Positive views of the future

* True commitment to personal values

* Strong sense of personal efficacy

* Wise investment of personal energy

* Courage to act on convictions

These strengths were considered considering the aspects or areas in which school leaders can display resilience in the midst of trying times. School leaders should be able to learn from the past and apply those learning in present situation, whenever applicable. No matter how the flaws in the past have contributed in for unprecedented failure, a resilient leader would still look at positive outcomes in the future. They may be tested by dilemma on whether they will sacrifice personal value for a remarkable achievement, but a resilient will not bend along the road of character test. He or she looks at attaining the objective or goals so as to maintain high efficacy. Resilient leader would never waste energy on something that will not contribute to the attainment of the goal. Lastly, resilient leaders act on strong, founded convictions and not on surge of emotions.

\subsection{Conceptual Framework}

A school leader must be resilient at all times especially now that the country is facing a devastating event that challenges various sectors including the field of education. There are four (4) factors or areas that under the school leader's resilience namely the promotion of community cohesiveness, sustained communication, welcoming feedback, and attention to mental and psychosocial health. These factors must be taken into consideration for the school leader to effectively and efficiently adapt in the face of adversity.

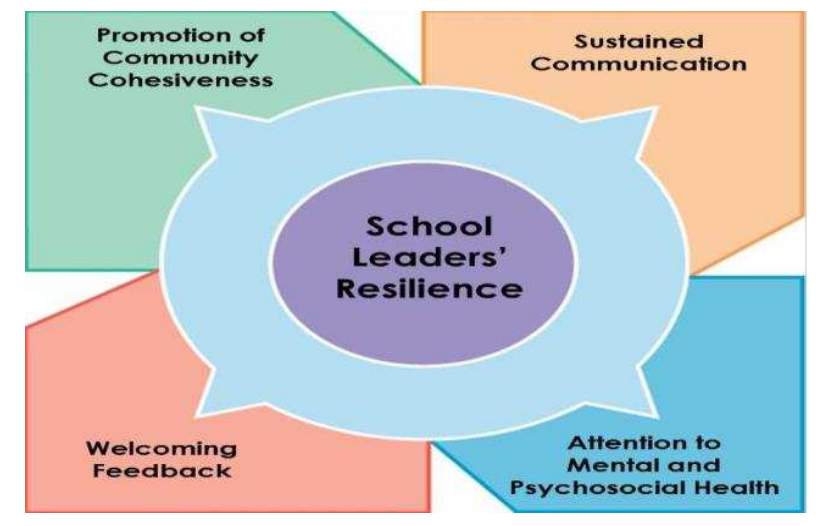

Fig. 1. The research paradigm

Promoting community cohesion should be one of the goals of the school and the school leader in these times. Amidst the pandemic, tragedy, and significant sources of stress, a school leader must still be resilient. He/she should be flexible in finding ways to provide support and extended services to the learners, 
teachers, and stakeholders of the school. The presence of effective and regular communication between the school and the stakeholders should still be visible. Good communication will make the school productive and is conducive to understanding the needs of the stakeholders. Through sustainable communication with the community, the school leader can easily think of possible solutions to certain problems and construct activities or programs that would help the community. Meanwhile, a school leader should also be open to the feedback of the stakeholders. An organization that welcomes the opinions of its stakeholders is effective and productive. Also, a school leader gives attention to the mental and psychosocial health of the school's stakeholders. Conducting seminars that promote healthy mental and psychosocial health and keeping in touch with the learners, teachers, and stakeholders is a good way of showing how resilient a school leader is.

\subsection{Statement of the Problem}

This study focused on exploring the different ways in which school leaders in Victoria, Laguna were able to continue delivering quality education amidst pandemic.

Specifically, it sought to answer the following questions:

- What is the mean level of resiliency of the school leaders in terms of the following:

a. Promotion of community cohesiveness;

b. Sustained communication;

c. Attention to mental and psychosocial health;

d. Welcoming feedback;?

- How can schools promote a cohesive community among teachers, learners and stakeholders?;

- What can schools do to have a sustained communication and continuous delivery of important information?;

- How should mental and psychosocial health be prioritized in this time of pandemic?; and

- In what ways can feedback be gathered and dealt with so as to provide action or solution?

1.5. Significance of the Study

Through the study, the following persons or group of persons will be benefitted:

- Students - Academic Achievement should not be affected by the existing pandemic. Resiliency of school heads is a great factor so that each learner will be able to finish their studies this school year.

- Teachers- Knowing that path of the school through the resiliency of the school head will still achieve better learning outcomes from the students and a better school performance.

- School Heads- Leading the school is not that easy especially in this time of pandemic. Resilient leaders direct his organization in the right path even facing challenges in education.

- Parents- Every parents long to have their children completed their studies and not to miss a class. Lagging behind in lessons will not be anymore their problem.

\subsection{Scope and Limitation}

This study will make use of the 17 school heads in the District of Victoria, Victoria, Laguna as the respondents in questionnaire. The concepts or conclusions formed may be seen as applicable only during this time of pandemic but the general ideas can cover times of normal situation, as collaboration to parents and community, constant communication, welcoming feedback and attention to psychosocial and mental health are all important aspects for a growing and developing institution.

\section{Related Readings}


This section cites related readings to the present study. They will give light to the different issues or variables concerned to the focus of this study.

For school leaders working in these demanding and chaotic circumstances, the pressure is relentless, the options are limited, and the sleepless nights are frequent. The staff meetings, coffee catch ups and corridor chats with colleagues, which made up a school day, have gone. All those informal, important, moments where social relationships are built, and leadership is enacted simply vanished overnight. Parents, students, and teachers now exist in a twilight education world either awaiting the return of normal service or hoping for some new normal that might offer stability, continuity, and reassurance. The stark reality is that neither is likely to occur anytimesoon.

Meanwhile, school leaders are caught in the unfavorable position of being the pinch point in the system. They are reliant on guidance about COVID-19 responses, processes, procedures, and protocols from above. These can change, almost overnight, depending on how the virus develops. Simultaneously, school leaders are dealing with fluid and changing staffing situations meaning they are having to do much more with less. The social distancing of staff and students means extra work and extra pressure on those staff who can return to work. Every expectation either from aboveor below asks more of school leaders professionally and personally.

This perfect storm with imperfect leadership needs attention nowadays. As Netolicky (2020) noted in time of crisis, leaders must act swiftly and with foresight but also with careful tightrope without a safety net. There are no precedents and no guides to leading schools in a pandemic. There has been some early research, of course into the effects and impact of COVID 19 on all sectors of education. This work has helped to set down useful markers and some preliminary reference points. Aiming to capture the dimensions of such a colossal moving target, however, will require far more sophisticated research methodologies in the future, if the work is to move to more valid and generalizablefindings (Fetters and Molina-Azorin 2020).

Despite a current lack of research on how school leaders are responding to the pandemic, there are some emerging insights about leadership within the COVID19 educational landscape. The following seven propositions are offered for considerationand possibly, in due course, empirical attention.

- School leadership practices have changed considerably and maybe, irreversibly because of COVID19. As a result of the pandemic, school leadership has shifted on its axis and is unlikely return to 'normal' anytime soon, if ever at all. Research underlines that the principles of good leadership are a constant i.e. having a clear vision, developing others, managing people, building capacity etc. (Leithwood, Harris, and Hopkins 2020). The evidence also points towards the importance of context responsive leadership implying a shift in school leadership practices because of COVID19 (Harris 2020).

- Most school leadership preparation and training programmes prior to COVID19 are likely to be out of step with the challenges facing school leaders today. In many cases, the existing preparation and training programmes, along with the models of leadership they espouse, will require a radical re-think and significant modification to remain relevant for aspiring and practicing school leaders. It would be a mistake to simply re-configure or re-badge what was relevant before ongoing, COVID19 situation.

- Self-care and consideration must be the main priority and prime concern for all school leaders. Leading a school through the changes and challenges that accompany COVID19 and post COVID19 will require school leaders who put their own health and wellbeing first, so that they will be able to help others. Increasingly, school leaders are managing the emotional responses of others to this crisis including anxiety, frustration loss, and anger. Consequently, self-care must be a priority for those leading schools at all levels.

- The phrase 'connect to learn, learn to connect' (Harris and Jones 2012) describes the daily reality of students and teachers trying to work together in this pandemic. Hence, moving forward, school leaders will increasingly need to be technologically savvy and well informed. COVID19 has generated huge commercial opportunism with a pressure to buy technological solutions to contemporary problems. School leaders will need to be discerning therefore, about the digital products they choose and to be careful about striking a balance between technology and pedagogy in their school (Hargreaves 2020). Ultimately, pedagogy is the key to effective learning and while technology has a part to play, it is the 
human dimension of effective teaching that makes the difference.

- Crisis and change management are now essential skills of a school leader. Running an effective school in disruptive times will require more than routine problem solving or occasional firefighting. Instead all school leaders will need to be engaged in constant crisis and change management which will require supportand collaboration from all staff. The speed of change in this pandemic is unprecedented hence, a high degree of trust will be needed, as the collective glue, to ensure that issues are addressed collectively as they arise. parent/community groups to support families, young people and children is now a necessity to deal with the many issues that COVID19 has generated particularly for vulnerable, marginalised, or isolated young people.

- Distributed leadership has become the default leadership response in this current crisis requiring more school leaders, at all levels, to connect, share, learn and network their way through issues (Azorín, Harris, and Jones 2020). Through absolute necessity, rather than by design, effective school leadership is now connected, collaborative, creative and responsive. Most school leaders will be running on empty given the myriad of challenges that COVID19 has created forthem, so distributed leadership is a necessity to survive.

As we move forward to construct our "new normal" in the wake of the COVID-19 pandemic, we must therefore recognize that along with the economy and health care system, schools are an essential third pillar in promoting community resilience and rebuilding communities' physical, economic, emotional, social, and cultural health. Supporting schools amid the pandemic is thus about much more than re-configuring learning opportunities, as crucial as that is. In fact, focusing solely on schools' capacities to provide high-quality remote learning opportunities to students at scale may perversely weaken communities by failing to recognize schools' diverse and far-reaching roles in promoting community resilience through non-teaching roles such as child care, social welfare services, and stable adult employment. Pandemic-resilient schools can (and are essential to) contribute to a pandemic-resilient society (Allen et al., 2020) when they are capable of fulfilling each of the five essential roles they have historically played in promoting pre-pandemic community resilience: social welfare services, human development, child care, employment, and democratic solidarity. Yet the long-term closures that the pandemic requires have made it difficult, if not impossible, for schools to perform any of these roles. The shift to remote education has laid bare deep educational in-equities, as many students are not able even to access online schools or much-needed resources. With brick-and-mortar schools closed, parents across the country struggle to balance child care, educational instruction, and their jobs. And schools' role as employers - in many communities the single-largest lo- cal employer capable of providing middle-class or living wages - is facing the threat of severe budget cuts that may force them to lay off or furlough substantial portions of their workforces (Litvinov, 2020; Strauss, 2020). Even when schools have been able to sustain one of these crucial roles-namely, their ability to continue food distribution to students and families-cracks have become evident. Many eligible families have been unable to pick up food because of essential work schedules or lack of transportation (DeParle, 2020), and increasing numbers of Americans who are food insecure for the first time because of the pandemic-induced shutdown are reaching out to schools for support (Bauer, 2020). It isunclear whether schools have the resources to meet this growing need.

As the pandemic continues to shake the foundations of the country's economy and social fabric, schools need support along each of the five dimensions of community resilience so that they, in turn, can sup-port the families and communities who rely on them in so many different and vital ways. In what follows, we detail each of these sources of resilience and the impact of the pandemic on schools' ability to real-ize them. We then offer a series of recommendations for policymakers that would enable schools to sustain communities during this moment of global crisis.

K-12 schools also provide physical and mental health services to millions of students per year, including vaccinations; management for chronic diseases such as diabetes, asthma, or ADHD; sexual and reproductive health education and services; vision, dental, and mental health screenings and services; nutrition health education; and hypertension screening (Baltag et al., 2015). School nurses and counselors are particularly 
powerful providers of care (Maughan, 2018); recent studies have found that about three-quarters of students who receive any mental health services get them in their schools, for instance, and that students are "21 times more likely to visit school-based health centers for mental health services get them in their schools, for instance, and that students are " 21 times more likely to visit school-based health centers for mental health than community mental health centers" (Whitaker et al., [2019]). Although the nationwide shortage of nurses has made it hard for schools, like community health centers and hospitals, to maintain adequate staffing levels (Washburn, 2019), U.S. schools stillemploy approximately 95,800 FTE nurses to serve a population of about 55 million students (Willgerodt,2018). Vital health services are also provided by 111,000 school counselors, 32,000 social workers, and 41,000 school psychologists (as of 2012; see NCES, 2012). Often these providers are the first point of care, especially in under-resourced areas (Whitaker et al., [2019]); about a quarter of students served by a dental outreach program in Michigan, for example, had never seen a dentist before (Albanese, 2014), and over 6,500 students in Baltimore Public Schools have received glasses since 2016 thanks to schoolbased screenings (Hub Staff, 2019). Unfortunately, availability does not fully match need. The most vulnerable students often attend schools in districts with the worst ratio of counselors and nurses to students (Willgerodt et al., 2018; Gagnon \& Mattingly, 2016; CLASP, 2015). This is one of the reasons teachers went on strike in Los Angeles Unified and Oakland, California, in 2018 and 2019; the unions made increased nursing capacity a key demand (Washburn, 2019) and won concessions inboth cases.

Modern societies rely on two central institutions to work in tandem to support children's educational development - the school system and the family. This partnership supports community resilience in twodifferent ways. First, schools are vital partners in the shared work of child development. While children's home environments have significant impact on their school-based learning (Coleman, 1966; Osher et al., 2020; Reardon, 2011), schools are primary sites of formal academic, social-emotional, civic, and vocational learning for the vast majority of children in the U.S. As many parents have been dismayed to discover while trying to home-school during the pandemic, teaching algebra, reading, coding, or music requires specialized knowledge and skills, which professional teachers have and parents generally lack. By bringing numerous children and adults together into one shared space, schools also provide young people opportunities to develop friendships and other meaningful relationships, to develop emotional regulation and executive function skills beyond the family setting, to develop civic knowledge and habits of civic engagement, and to gain valuable workplace skills including group work skills and vocation- specific skills such as nursing or car repair. Schools can also harness economies of scale unavailable to families because a single teacher can educate multiple children at a similar stage of development at a time. Furthermore, schools can improve the prospects of students whom our society systematically disadvantages in other ways. U.S. schools are characterized by deep disparities in achievement and opportunity, by race and class in particular, but there is also good reason to believe that without schools, these disparities would be even larger (Reardon, 2011; Center on Education Policy, 2007).

Second, schools support long-term community resilience by providing individuals with the knowledge and skills necessary for sustaining collective community life. In addition to the effects of education for individuals, we all collectively benefit from higher levels of educational goods in the population. High levels of education enable greater economic productivity, quicker and better solutions to social and economic problems, and greater and more complex cultural production, not to mention healthier and longer lives (Sen, 2009; Mcgregor, 1994; Moretti, 2004a, 2004b). Never is this clearer than in a major public health crisis in which we rely not just on the dedication and commitment of health professionals, but also on their knowledge and skills.

Yet, the pandemic has disrupted the traditional division of labor between families and schools, affecting both the short- and long-term ways that human development supports community resilience. Schools typically promote human development through embodied, synchronous interaction: teachers and students are in the same room at the same time, and whatever work they do outside that room, alone or with others, is organized around that embodied interaction. That is exactly what schools cannot do during a pandemic: public health precautions require teachers and students to be physically isolated fromone another. 
Schools have thus shifted to using alternative modes of delivery. In fact, in just eleven days during the pandemic, the percentage of schools providing remote learning increased from 43 to $71 \%$ (Malkus \& Christensen, 2020b), and by late April virtually all schools and districts had remote learning plans in place (Malkus \& Christensen, 2020c). Despite classroom closures, teachers in $60 \%$ of schools have been encouraged to connect with their students through synchronized video lessons, independent- learning platforms, or email (Malkus \& Christensen, 2020a). But without training, practice, preparation, or a proven infrastructure, these efforts have proven to be substantially less effective at driving learning than traditional inperson modes of instruction (Goldstein, 2020; Reich et al, 2020). Furthermore, the evidence suggests that the "online penalty" (Dynarski, 2018) has proven even harsher for already vulnerable students, in particular lowincome students, students with disabilities, and students in historically marginalized schools and communities (Goldstein, 2020).

Most parents are ill-equipped to step fully into teachers' educational roles even under propitious circumstances. Teaching is already a complex task that requires professional judgment and expertise that most parents lack (Alterator et al., 2018; Parker \& Hess, 2001; Shulman, 1986). On top of that, most parents are either trying to balance an increased role in educating their children with the other job they were already doing, or are trying to educate their children while they endure the stresses associated with the loss of the job they were previously doing (Long, 2020; Harris, 2020). The vast majority of parents cannot simply step into the role of teacher and do so effectively.

Public health concerns justify the closure of schools in most places right now, despite the costs to individual and collective human development. But there is every reason to suspect that those costs will be substantial (Dorn et al., 2020). This will be especially true for students whose families are particularly stressed by the virus, whether because they are in populations that are disadvantaged due to U.S. socioeconomic and racial structures, or because their parents work in positions that are vulnerable to infection, or because they are sick, or because they have special educational needs (Kelly \& King, 2020; Kufeld \& Tarasawa, 2020). Parents struggle as a result of school closure in different ways given the varying impact of the pandemic on their ability to work. Far too many parents have lost their jobs as a result of the pandemic. In addition to providing care for their children, they may be searching for work, navigating overwhelmed unemployment offices, or fighting with landlords about rent (McCarthy et al., 2020). Most parents of school-age children who have not lost jobs continue to work. Yet now they must do so while they balance childrearing full-time - a challenge that has led to reported declines in family well-being within a week following a stay-at-home requirement (Ananat \& Gassman-Pines, 2020). Through social media and widely shared opinion columns, parents offer glimpses into their reality. Two-parent families struggle to adapt to various coping strategies, including alternating work hours or working early or late in the day if their job allows (Manjoo, 2020), while single-parent families face even steeper obstacles (Bobrow, 2020). Some schools have attempted to ameliorate parents' child care obligations through providing synchronous classes or assigning projects and other school work designed to occupy students for long stretches of time. While this has proved a boon for some families, it has imposed additional burdens on others whosechildren need extra support to access the technology or complete the work. Particularly for families with young children, children with special needs, or multiple siblings, managing school work adds to the child care burden rather than relieving it (Cavanagh \& Fox, 2020; Parcak, 2020).

Schools serve as sites and sources of community resilience in five distinct ways: they distribute social welfare services, promote human development, care for children, provide stable employment, and strengthen democratic solidarity. Yet long-term physical school closures-along with impending budget cuts driven by cratering state and local economies and tax revenues-make it extremely difficult for schools to perform any of these roles. We recommend three steps for restoring schools' capacities to support community resilience. First, state and district leaders should set metrics for achieving access and equity in each of the five roles that schools play, not just in academic achievement. Second, to establish these metrics, policymakers should develop or strengthen mechanisms to engage diverse community voices, as local community members 
often best understand the specific ways in which their own schools support or impede community resilience. Finally, Congress should allocate significant increases in federal funding to support public schools and districts for at least the next two years; these allocations should include strong supports for high- needs districts in particular.

\section{Research Design and Methodology}

\subsection{Research Design}

The exploration design used to reach the intended objective of this study is qualitative. Cresswell (2003) characterizes qualitative research as focusing on collecting open-ended emerging data with the primary aim of developing themes from the data. There are three characteristics of a qualitative research. (1) qualitative data collection is open ended, (2) qualitative data analysis is based on text and (3) qualitative process is iterative. All of these characterized the design used in producing this study. Questions solicited to the school heads- participants are open ended and they were asked to explain answers comprehensively using google forms. Analysis of data is based on their answers during the online survey. The process of analysis is iterative in a sense that the frequently appearing words studied and analyzed based from the responses.

\subsection{Respondents}

The respondents of this study are the 17 school heads of Victoria District, Victoria Laguna. This study was conducted school year 2020-2021.

\subsection{Data Gathering Procedure}

The researcher sought to determine the School Heads' Resiliency in Victoria District, Victoria Laguna through informed consent to conduct the online survey. After the permission was secured, survey, online survey questions was uploaded in a google form and encoded them. Then data from the answered survey questionnaires was tallied and treated statistically for the interpretation.

\subsection{Ethical Considerations}

To answer ethical concerns that have direct and indirect relation to the present study, the seven-point ethical issues are answered here:

- Social value - The relationship and social value is protected since the method used is online survey and the respondent's names were not required.

- Scientific validity - The researcher asked the help of an expert to scientifically treat the data using statistical treatment fitted for the data gathered. Scientific validity was attained because was no jumping into conclusion that happened. Only conclusion which was backed up with results of treatment were presented in this research.

- Fair subject selection - There were no emotional or relational biases among the researcher and the respondents.

- Independent review - Analysis and interpretation of data were carefully done. Only the plain data from the responses were treated.

- Informed consent - School heads were informed beforehand that online survey would be given to them. The data would come from the result of the online survey.

- Respect for enrolled subject - Name of school heads were not revealed here because the focus was their resiliency in the new normal in education. 


\subsection{Data-Gathering Instruments}

To answer statements of the problem, the following instruments were used:

For statement of the problem number 1, an online survey questions was used to find the mean level of resiliency of the school leaders in terms of promotion of community cohesiveness, Sustained communication, attention to mental and psychosocial health, and welcoming feedback using the Likert evaluation system.

4.21-5.00 very high level of resilience

3.41-4.20 high level of resilience

2.61-3.40 moderate level of resilience

1.81-2.60 Fair level of resilience

1.00-1.80 Poor level of resilience

For statement of the problem number 2-5, an open-ended interview was done using also the google form platform.

\subsection{Data Analysis}

The statistical treatments will be used for this study:

For statement of the problem number 1 mean and standard deviation were used to measure school heads' perception in terms of promotion of community linkages, sustained communication. Welcoming feedback and attention to mental and psychosocial health.

For statement of the problem numbers 2-5, thematic analysis was implemented, in which, the responses from the school leaders were encoded and analyzed so as to produce resounding concepts that answer each concerns in the statement of the problem.

\section{Presentation, Analysis and Interpretation of Data}

This section lay out the result of the study. All questions in the statement of the problem are carefully answered through the presentation, analysis and interpretation of the results.

\subsection{Mean Level of School Heads' Resiliency}

Table 1. The school heads' status of resiliency

\begin{tabular}{|l|c|c|}
\hline \multicolumn{1}{|c|}{ Items } & Mean & Interpretation \\
\hline 1. Promotion of community cohesiveness & & very high level of resilience \\
& & \\
\hline 2. Sustained communication & 4.25 & very high level of resilience \\
\hline 3. Attention to mental and psychosocial health & 4.52 & very high level of resilience \\
\hline 4. Welcoming feedback & 4.50 & very high level of resilience \\
\hline \multicolumn{1}{|c|}{ Average } & 4.44 & very high level of resilience \\
\hline
\end{tabular}

Legend: $\quad 4.21-5.00$ very high level of resilience

3.41-4.20 high level of resilience

2.61-3.40 moderate level of resilience

1.81-2.60 Fair level of resilience

1.00-1.80 Poor level of resilience 
The table above shows the mean level of resiliency of the school heads in terms of promotion and cohesiveness, sustained communication, attention to mental and psychological health, and welcoming feedback.

The four items all corresponds to the rate of the 17 school heads in Victoria District.

All items received very high level of resilience rating. Overall, the school heads received very high level of resilience rating (4.47) which means that the school heads are doing their tasks to adopt in the new normal.

\subsection{School heads' promotion on a cohesive community among teachers, learners, and stakeholders.}

School heads can promote community cohesion by engaging families and stakeholders in all the programs, understanding the common goals, roles, and responsibilities of each other, and ensuring the safety of all because school is a place where we can do our job successfully and nothing to worry about.

When it comes to communication the school heads can use different platforms in promoting a cohesive community and informing the stakeholders of what the school has been accomplished thru social media because nowadays it has been widely used in the country. Clear and regular communication in social media and on any platform is needed because it gives importance to the internal and external stakeholders of the school. They should be open to feedback and address them so that a two-way process is being utilized. This can be done through constant dialog and communication with the school community, getting their take on the affairs of the school, and conducting a meeting for everybody's concern. These actions elucidate a strong information dissemination system. When there is strong communication in the school it would be easy to support each other, extend help in times of need, have a constant follow up on the delivery of lessons on printed modules, provide activities that all the internal and external stakeholders will collaborate, and have a consistent update in projects and programs to be implemented for school's development.

Furthermore, every action must be based on the legality of following DepEd orders, memo, guidelines, policy, and practices because it is vital to establish a strong foundation of general knowledge and understanding of current affairs as well as fulfilling the school's duties to encourage community cohesion.

The first theme developed about school leaders' resilience is:

"School heads can promote community cohesion by engaging families and stakeholders in all the programs."

\subsection{School heads sustaining communication and continuous delivery of important information}

School heads should establish a direct line of communication through different platforms because this will enable the school to relay the information as the need arises. Since the workforce is skeletal these times, virtual communications are the best way to have a sustained communication and continuous delivery of important information. Weekly meeting and daily updates through the use of social media application are very effective in talking about the needs and solutions to the problems which will arrive. With the aid of social media school head, teachers, learners, and the community can communicate to discuss everything to make them informed of the latest issues in our system.

Communication strategies should be adapted to address the needs of the learners and parents. Schools should have an extra internet connection in reaching out through FB messenger, calls and text are some ways of communicating with the learners and parents. The school can use the group chats to sustain the delivery of information, regular posting of information on the official page, and in seeking the help and support of LGU, NGO, and other community associations. The use of the comment section in the Facebook posts in the FB group can also be utilized. Open communication is a must and availability has to be seen at all times.

Monitoring and Feedback are also an important part of every delivery. It gives details on how to 
improve and sustained every action to make. The school has no limit for any kind of questions given by the stakeholders and accepts their ideas and recommendations for the betterment of the school.

The second theme developed about school leaders' resilience is:

"School heads School heads establish a direct line of communication through different platforms."

\subsection{School heads welcoming feedback which was gathered and dealt with to provide action or solution}

Feedback is an essential tool in tracking the performance of every student especially in this modular distance learning where students are studying at home through the supervision of the parents. Appropriate strategies must be employed in feedback monitoring to fully grasp how students performed on their studies.

Feedback can easily be gathered through the means of communication between parents, teachers, and students with the use of FB messenger, call, and text. School can also provide dropbox accessible to all. Using the power of the internet, feedbacks will give action and solutions for better delivery of education. It can be done through direct interaction with parents, pupils, and other stakeholders, but it depends on the level of concern being raised.

Meanwhile, feedback can likewise be gathered via suggestions and comments boxes, via meeting stakeholders physically or virtually, by using school monitoring form, writing reflections weekly so that immediate action be given, and giving questionnaires or answering Google forms. It can also be easily interpreted by applying the right statistical treatment. Consolidation must be done to gather the most arising improvement or sustainability to address things that important in providing action or solution. With the feedback, we were able to address necessary interventions.

"The third theme developed about school leaders' resilience is: "School heads tracked the performance of every student."

\subsection{School Heads' attention to mental and psychosocial health be prioritized in this time of pandemic}

Mental and psychosocial health is very important and must be prioritized to prepare the teachers, learners, and other stakeholders physically and mentally. Along with our efforts to combat the epidemic, we must acknowledge and manage our mental health during this adverse period. Teachers, parents, and learners must exercise self-care and establish a routine to avoid stress to harbor positivity. Nutritious diet and exercise should be on the daily basis to stay healthy and must ensure the safety and security of the teachers, learners, and stakeholders through proper scheduling in the delivery and retrieval of learning materials.

The school has leniency and sensitivity to the situation of others. They give enough time for learners to do their tasks/ activities, and regularly send Bible verses, quotes, and stories via the internet. Teachers have their GC to communicate with parents and also give some instructions followed the psychosocial health protocol. Since some of the students, parents, teachers have experienced different obstacles in life this PSA very much helps to enlighten their minds. It also motivates them to pursue their life and help them to solve problems in different ways.

Moreover, DepEd's support to the teachers, parents, and students through virtual Seminars about mental and psychosocial wellness is very helpful. These help us become optimistic, positive, and productive. Virtual meetings/ webinars with the teachers, parents, and learners are also conducive in making them informed as to how to cope at this time of pandemic since this is the first time we encountered this. Transfer of information through webinars has to be provided for the teachers, parents, and learners. Brochure or pliers has to be distributed thru social media, and Links for video about mental health can also be forwarded to them aside from the webinars.

The fourth theme developed about school leaders' resilience is:

"School heads conducted virtual Seminars about mental and psychosocial wellness." 


\section{Summary, Conclusion and Recommendation}

This portion of the study lines up the conclusions resulting from the findings gathered from the responses of school heads, the recommendations that are deemed to sustain the smooth flow of school operation in times of pandemic, and the reflection of the author.

\subsection{Summary of Findings}

This study came into interest from the researcher because of the emerging need of looking into what is fitted nowadays in terms of school head's resiliency and to find out if they can bounce back in face of loss.

- a. School heads received very high level of resilience rating.

- b. (i). Clear and regular communication in social media and on any platform is needed because it gives importance to the internal and external stakeholders of the school

(ii). School heads used different platforms in promoting a cohesive community and informing the stakeholders of what the school has been accomplished thru social media

(iii). School Heads conduct regularly a virtual meeting for everybody's concern.

- c. (i). Since the workforce is skeletal these times, virtual communications are the best way to have a sustained communication and continuous delivery of important information

(ii). Weekly meeting and daily updates through the use of social media application are very effective in talking about the needs and solutions to the problems which will arrive

(iii). Communication strategies should be adapted to address the needs of the learners and parents

- d. (i). Appropriate strategies must be employed in feedback monitoring to fully grasp how students performed on their studies.

(ii). Feed backing address necessary interventions to stakeholders.

(iii). Feedback can be done through direct interaction with parents, pupils, and other stakeholders

- e. (i). Appropriate strategies must be employed in feedback monitoring to fully grasp how students performed on their studies.

(ii). Schools should have an extra internet connection in reaching out through FB messenger, calls and text are some ways of communicating with the learners and parents

(iii). Consolidation must be done to gather the most arising improvement or sustainability to address things that important in providing action or solution. With the feedback, we were able to address necessary interventions.

\subsection{Conclusion}

Based from the result of findings, the conclusion is made:

- The school heads received very high level of resilience rating (4.47) which means that the school heads are doing their tasks to adopt in the new normal.

- School heads promoted community cohesion by engaging families and stakeholders in all the programs

- School heads School heads established a direct line of communication through different platforms

- Feedbacks gave action and solutions for better delivery of education

- School heads conducted virtual Seminars about mental and psychosocial wellness

\subsection{Recommendation}

Considering the result obtained from this study, the following recommendations are given to target persons: 
- That School heads should live up with the challenging times by continually improving and implementing their school's learning continuity plan as the pandemic in the community still prevails.

- That District Supervisors should continue to provide technical assistance and professional advice to school heads under their care. Cheering school leaders up and providing moral support is a must need action from them so as school leaders would not feel they are alone in rowing the boat. Regular district feed-backing can be done so as to highlight best practices wherein schools can adapt and implement in their own context.

- That the Department Education provide clear-cut agenda for a certain period, implement them rigorously, and make a necessary evaluation, before shifting into a new scheme. Considering the base manpower in the system, the teaching force, is an important consideration because they are the ones who are implementing the learning continuity plan of every school, and they are the ones who are in front of the battle in terms of providing quality education to the youth. They need the provision of modules, they need trainings, they need adequate materials, and the likes, in which, if these would not be supplied in due time, they might experience low effectivity and low efficiency in terms of their performance.

\subsection{Reflection}

The life of the school leader isn't necessarily a stroll in the park. He or she is going to have issues that will cause her some struggles along the way but will also help her develop her character. Since a school leader can't escape adversity, what he needs to do is to improve things that need to be reinforced and to be a leader with substance. A school leader implements changes that would help the school stand amidst challenges and a role model that elucidates how to move forward during times of difficulty. No organization can stand without a leader, more specifically a resilient leader. During times of adversity, a resilient school leader will not be disheartened, instead, he is motivated to turn challenges and problems into achievement. He leads and inspires teachers, learners, and the community to work hard and help each other despite having their competence challenged. A resilient school leader influences the stakeholders of the school personally and virtually. He functions well in difficult times.

\section{References}

Albanese, Erin. (2014). “Dental Team Saving Teeth, School Days, in Districts High Need.” School News Network: A Window into Your Public Schools, posted November 13, 2014. https://www.school- newsnetwork.org/2014/11/13/dental-teamsaving-teeth-school-days-districts-high-need/

Allen, Danielle, Lucas Stanczyk, Rajiv Sethi, and Glen Weyl. (2020). "When Can We Go Out? Evaluating Policy Paradigms for Responding to the COVID-19 Threat." Edmond J. Safra Center for Ethics, COVID-19 Rapid Response Impact Initiative, White Paper 2. https://ethics.harvard.edu/when-can-we-go-out

Alterator, Scott, Craig Deed, and Vaughan Prain. (2018). "Encapsulating Teacher Expertise in Action." Teachers and Teaching: Theory and Practice 24 (4): 450-60.

Ananat, Elizabeth O., and Anna Gassman-Pines. (2020). "Snapshot of the COVID Crisis Impact on Working Families." EconoFact. March 30, 2020. https://econofact.org/snapshot-of-the-covid-crisis-im- pact-on-working-families

Azorín, C. , A.Harris, and M.Jones . (2020). "Taking a Distributed Perspective on Leading Professional Learning Networks." School Leadership \& Management 40 (2-3): 111-127. doi:10.1080/13632434.2019.1647418.[Taylor \& Francis Online], [Web of Science $\circledR$ ], [Google Scholar]

Baltag, Valentina, Anastasiya Pachyna, and Julia Hall. (2015). "Global Overview of School Health Services: Data from 102 Countries." Health Behavior and Policy Review 2 (4): 268-83. https://doi. org/10.14485/hbpr.2.4.4

Bauer, Lauren. (2020). "The COVID-19 Crisis Has Already Left too Many Children Hungry in America." Brookings, posted May 6, 2020. https://www.brookings.edu/blog/up-front/2020/05/06/the-covid-19-cri- sis-has-already-left-too-manychildren-hungry-in-america/

Buras, Kristen L. (2011). "Race, Charter Schools, and Conscious Capitalism: On the Spatial Politics of Whiteness as Property (and the Unconscionable Assault on Black New Orleans)." Harvard EducationalReview 81 (2): 296-331. 
Cavanagh, Emily, and Eleanor Goldberg Fox. (2020). "Some Parents Say They're Not Homeschooling during the Coronavirus Pandemic Because It's Too Stressful.” Insider, March 25, 2020. https://www. insider.com/parents-wont- homeschoolin-coronavirus-pandemic-because-of-stress-2020-3

CLASP. (2015). "Course, Counselor, and Teacher Gaps: Addressing the College Readiness Challenge in High-Poverty High Schools." Center for Law and Social Policy, June 2015. https://www.clasp.org/sites/ default/files/public/resources-andpublications/publication-1/CollegeReadinessPaperFINALJune.pdf

Cresswell, JW. (2003) Research Design: Qualitative, Quantitative and Mixed Approaches ( $2^{\text {nd }}$ ed). Thousands Oaks, CA sage

DeParle, Jason. (2020). "Hunger Program's Slow Start Leaves Millions of Children Waiting." New York Times, May $26,2020$. https://www.nytimes.com/2020/05/26/us/politics/child-hunger-coronavirus.html

Dynarski, Susan. (2018). "Online Courses Are Harming the Students Who Nee the Most Help." New York Times, January $19,2018$. https://www.nytimes.com/2018/01/19/business/online-courses-are- harming-the-students-who-need-the-most-help.html

Fetters, M. D. , and J. F.Molina-Azorin. (2020). "Call for Papers for a Special Issue on COVID-19 and Novel Mixed Methods Methodological Approaches During Catastrophic Social Changes.” Journal of Mixed Methods Research 14 (3): $281-287$. doi:10.1177/1558689820920098. [Crossref], [Web of Science ®], [Google Scholar]

Gagnon, Douglas J., and Marybeth J. Mattingly. 2016. "Most U.S. School Districts Have Low Ac-cess to School Counselors." Carsey Research, National Issue Brief \#108, Fall 2016. Universi- ty of New Hampshire, Carsey School of Public Policy. https://scholars.unh.edu/cgi/viewcontent. cgi?article $=1285 \&$ context $=$ carsey

Goldstein, Dana. (2020). "Research Shows Students Falling Months Behind During Virus Disruptions.” New York Times, June 4, 2020 (updated June 10, 2020). https://www.nytimes.com/2020/06/05/us/cor-onavirus-education-lost-learning.html

Harris, Elizabeth A. (2020). “It Was Just Too Much’: How Remote Learning Is Breaking Parents.” New York Times, April $27,2020$. https://www.nytimes.com/2020/04/27/nyregion/coronavirus-homeschool- ing-parents.html

Hargreaves, A. , and M.Fullan . (2020). "Professional Capital after the Pandemic:Revisiting And revising Classic Understandings of Teachers" Work.” Journal of Professional Capital and Community,https://www.emerald.com/insight/publication/issn/2056-9548\#earlycite . [Crossref], [Web of Science $\left.{ }^{\circledR}\right]$, [Google Scholar]

Harris, A. (2020). "COVID-19 - School Leadership in Crisis?" Journal of Professional Capital and Community . https://www.emerald.com/insight/publication/issn/2056-9548\#earlycite [Crossref], [Web of Science ®], [Google Scholar]

Harris, A. , and M.Jones. (2012). "Connect to Learn: Learn to Connect." ProfessionalDevelopment Today 14 (4): 13-19. [Google Scholar]

Hub Staff. (2019). “Setting Sights Higher: World Sight Day.” Johns Hopkins University, HUB, October 10, 2019. https://hub.jhu.edu/2019/10/10/vision-for-baltimore-sight-day/

Kelly, Mary Louise. (2020). "The Long-Term Effects of Months-Long School Closures on U.S. Children. Interview with Dr. John King Jr." NPR.org, April 24, 2020. https://www.npr.org/2020/04/24/844562989/ the-long-term-effects-of-months-long-schoolclosures-on-u-s-children

Kuhfeld, Megan, and Beth Tarasawa. (2020). "The COVID-19 Slide: What Summer Learning Loss Can Tell Us about the Potential

Impact of School Closures on Student Academic Achievement." NorthwestEvaluation Association, Collaborative for Student Growth, Brief, April 2020. https://www.nwea.org/con-tent/uploads/2020/05/Collaborative-Brief_Covid19-Slide-APR20.pdf

Leithwood, K. , A.Harris, and D.Hopkins. (2020). "Seven Strong Claims about Successful School Leadership Revisited.” School Leadership \& Management $40(1)$ :

Litvinov, Amanda. (2020). "Nearly 2 Million Education Jobs Could Be Lost-Unless the U.S. Senate Acts." Education Votes, June 9, 2020. National Education Association. https://educationvotes.nea. org/2020/06/09/nearly-2-million-education-jobs-could-belost-unless-the-u-s-senate-acts/

Long, Heather. (2020). "U.S. Now Has 22 Million Unemployed, Wiping Out a Decade of Job Gains.” Washington Post, April 16, 2020. https://www.washingtonpost.com/business/2020/04/16/unemploy- ment-claims-coronavirus/

Malkus, Nat, and Cody Christensen. (2020). "School District Responses to the COVID-19 Pandemic: Round 4, Halfway Through Closures." American Enterprise Institute, May 2020. https://www.aei.org/ wp-content/uploads/2020/05/School-DistrictResponses-to-the-COVID-19-Pandemic-Round-4.pdf

Manjoo, Farhad. (2020). "Two Parents. Two Kids. Two Jobs. No Child Care." New York Times, April 22 , 2020. https://www.nytimes.com/2020/04/22/opinion/coronavirus-parenting-burnout.html

Maughan, Erin D. (2018). "School Nurses: An Investment in Student Achievement." Phi Delta Kappan 99(7): 8-14. https://kappanonline.org/maughan-school-nurses-investment-student-achievement/ McArdle, Elaine. 2019. "The Middle of Somewhere." Harvard Ed. (Summer): 26-29, 48. https://www.gse.harvard.edu/news/ed/19/05/middle-somewhere

McCarthy, E., Gibson, C., Andrews-Dyer, H., and Joyce, A. (2020). “A Working Mom's Quarantine Life.” Washington Post, May 6, 2020. https://www.washingtonpost.com/lifestyle/2020/05/06/coronavirus-pandemic-working-moms-quarantinelife/?arc404=true

Parcak, Sarah. (2020). @indyfromspace. Twitter post, April 8, 2020, 6:57 am. https://twitter.com/indyfromspace/status/1247856156963409920

Reardon, Sean F. (2011). "The Widening Academic Achievement Gap between the Rich and the Poor: New Evidence and Possible Explanations." In Whither Opportunity? Rising Inequality, Schools, and Children's Life Chances, edited by Greg J. Duncan and Richard J. Murnane. New York: Russell SageFoundation.

Patterson and Keheller (2005) Resilient School Leaders: Strategies for rninf Adversity Into Achievement” ISBN 978-1-4166-0267-5

Sen, Amartya. (2009). The Idea of Justice. Cambridge, MA: Harvard University Press.

Whitaker, Amir, Sylvia Torres-Guillén, Michelle Morton, Harold Jordan, Stefanie Coyle, Angela Mann, and Wei-Ling Sun. (2019). Cops 
and No Counselors: How the Lack of School Mental Health Staff Is Harming Students. American Civil Liberties Union, March 4, 2019. https://www.aclu.org/sites/default/ files/field_document/030419-acluschooldisciplinereport.pdf

Washburn, David. (2019). "Even When Districts Want More School Nurses, They Have Trouble Find- ing Them.” EdSource, February 24, 2019. https://edsource.org/2019/even-when-districts-want-more- school-nurses-they-have-trouble-finding-them/609022

Willgerodt,MayumiA.,DouglasM.Brock, andErinD.Maughan.(2018).“PublicSchoolNursingPracticeintheUnited States.” Journal of School Nursing 34 (3): 232-44. 